\title{
Reducing and Optimizing Tailgate Closing Effort in Automotive Car
}

\author{
S.Thavamani ${ }^{1}$, G.Devaradjene ${ }^{1}$, K. Yogeshkumar ${ }^{2}$ \\ ${ }^{\text {I}}$ (Dept. of Automobile Engineering, Madras Institute of Technology, Anna University, Chennai, India \\ ${ }^{2}$ FORD India P Ltd, Chennai, India
}

\begin{abstract}
This Project investigated the scope of automotive tailgate closure closing effort and optimization. Tailgate closing effort can be reduced with the aid of car body dimensional analysis and corrections. Dimensional analysis mainly deals about dimensional position of car body, seal gap at rear tailgate closure, margin and flushness between tail lamp and tailgate, bumper and tailgate, roof and tail gate. Dimensional position investigates car body and sub assembly manufacturing controls to ensure dimensional repeatability by using fixture integrity concepts, and incoming level supplier part dimensional variations. Fixture integrity concepts mainly focus to bring the car body towards nominal of its dimensional position. Seal gap at rear tailgate closure is a gap between weather strips mounting at framed body flange to tailgate resting surface. More seal gap gives less closing effort, more wind noise and less seal gap gives more closing effort, less wind noise. Margin and flushness between outer peripheral supports wind noise. Closures closing effort, Wind noise and air leak is integrated parameters in automotive car body.
\end{abstract}

Keywords: Closing effort, Tailgate, Seal gap, Margin and Flushness, Weather strips CLD.

\section{INTRODUCTION}

Passenger car is a wheeled motor vehicle used for transporting passengers, which also carries its own engine or motor. Tailgate is the closing door of luggage compartment. It provides the aesthetic outer appearance to the vehicle as well wind flow aerodynamic surface. Tailgate is single stamped outer panel. It integrates with inner reinforcement panel. To avoid air rushing noise as well metal rubbing noise, protected with sealer application process. Outer edges hemmed by Robot hemming process with 3 pass hemming to ensure sealer fill rate uniformly as well clinch tightness rigidly. in such a way easy to open at the same time, it should not pass external environmental noise inside the passenger compartment and should not leads to any water leak. High closing effort leads to improper locking, user's fatigue. NCT Manuals describes that desired state of tailgate closing effort is 70N maximum [1]. Markus Kevis [2] describes importance of Seals, latch, check link, Hinge design for door closing velocity. Above are mainly depends on Car body dimensional positions. Dariusz Ceglareknd [3] explained methodology and findings of root cause of dimensional variation in automotive body assembly. These activities should be established early in the product development process which will help to contain in pre-production phase. This paper specifically deals on master control definition and its usage. L.M.Sanches Jr [4] shared case study and results of a pre control method that allows for detecting subassemblies variations with low investments using a methodology that search an improvement in quality of automotive body-in-white assemblies joining processes through dimensional control. The dimensional repeatability and reproducibility will gives better result in Seal gap and Margin flushness which are key parameters for tailgate closing effort. F.Keith[5] describes the procedure involved stamping and assembly variation, body measurement system and process validation. It also deals importance of measurement system and is to verify repeatability and reproducibility to estimate accuracy for non-rigid sheet metal parts. Second Important Parameter is Weather strip CLD(Compression Load Deflection). A. Stenti [8] helped to understand structure brone vibration transmission of a highly nonlinear type of a joint a car door weather seal. Joseph Thomas [9] describes on various natural rubber material mechanical properties which may use as weather strip for Door and swing gate or tailgate in passenger cars. Rubber material CLD (compression Load deflection) properties.

\section{TAILgate Closing EFForT}

Master car Model Car Tailgate closing effort trend is shown in Fig 1, which is initial state of investigation. It describes Vehicle not meeting the desired state of $70 \mathrm{~N}$ of tailgate closing 
effort.

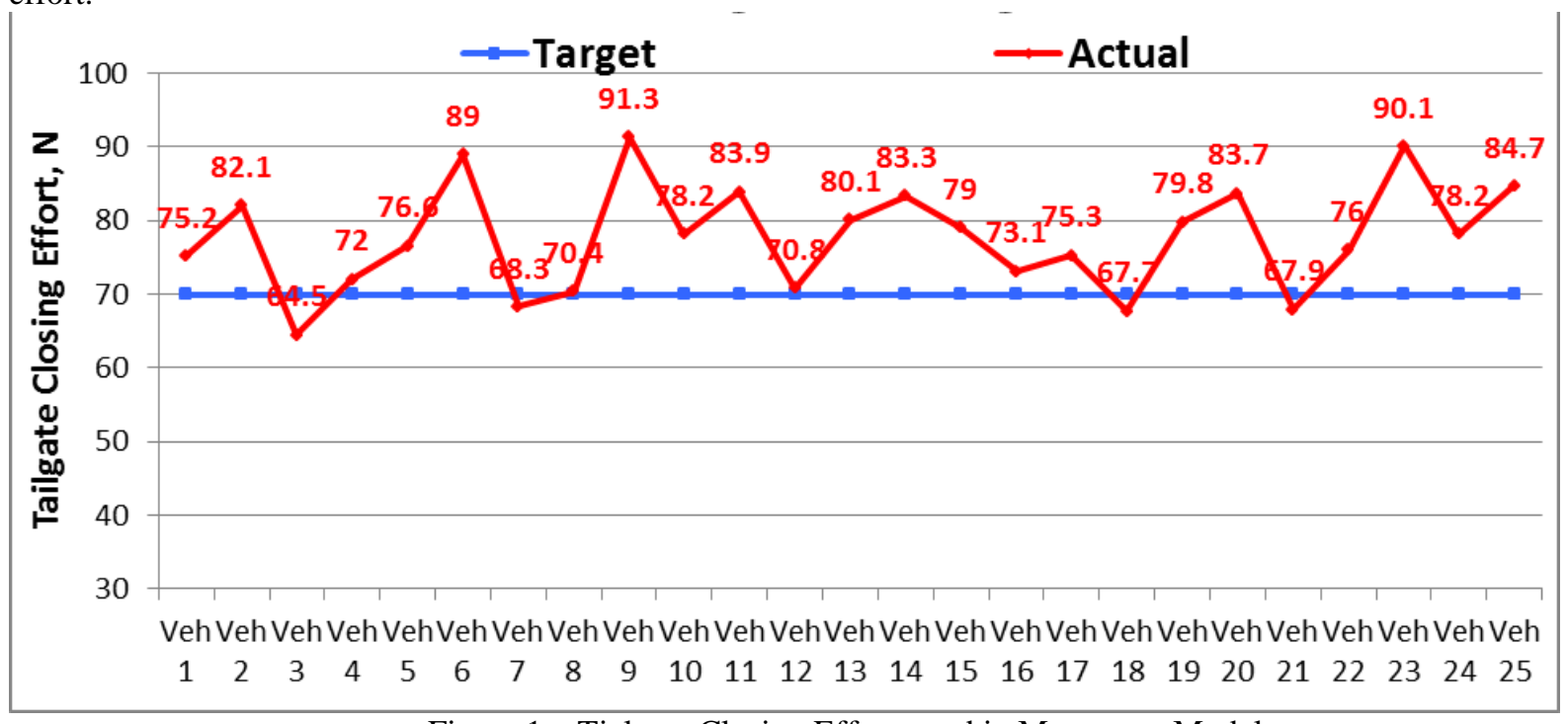

Figure 1 - Tialgate Closing Effort trend in Master car Model

Reducing tailgate closing effort to $70 \mathrm{~N}$ to achieve Desired State by addressing all possible root causes.

1. To bring the body shell towards nominal dimensional position.

2. Identify critical Xs for Tailgate closing effort control parameters

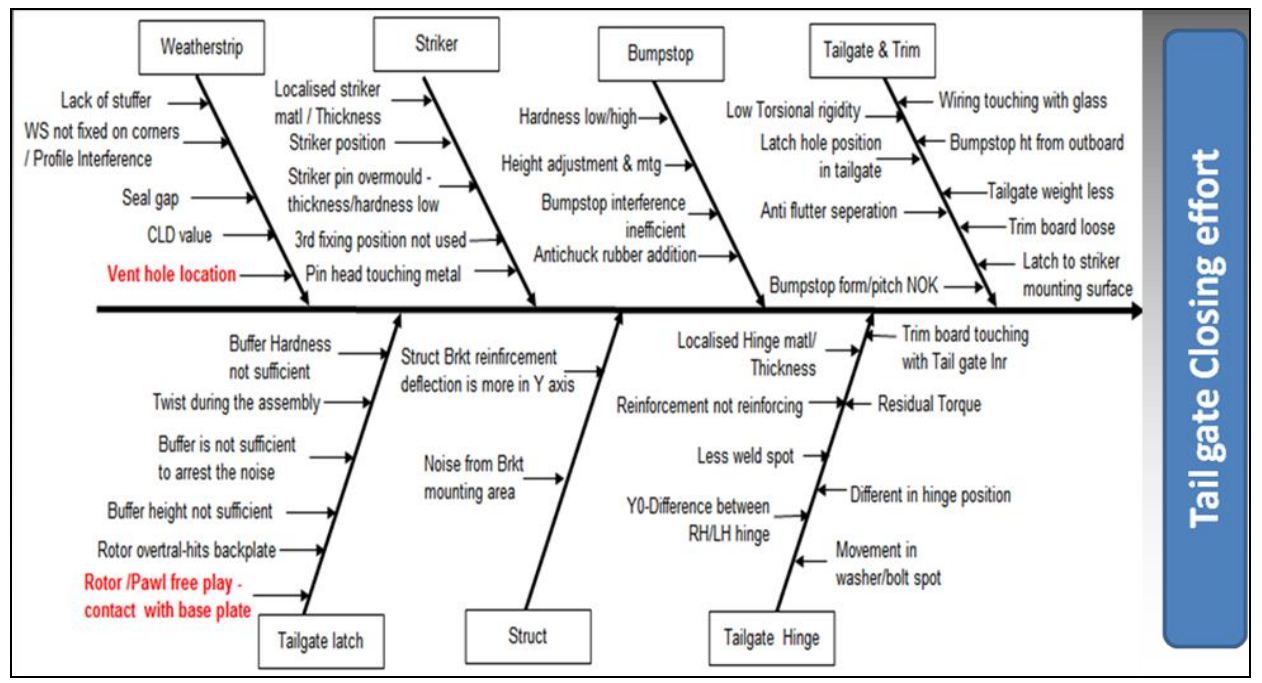

Figure 2 - Root Cause Analysis

All possible root causes can be identified with the aid of 7 QC tools, one the tool Cause and Effect Diagram as shown in Fig 2.

Factors to be considered:

1. Incoming level Sole part dimensional variation

2. Sub assembly rear end dimensional stability

3. Framed body dimensional capability

4. Rear end Seal gap

5. Weather Strip Analysis

\section{RESULTS AND DISCUSSIONS}

1. IMCOMING LEVEL SOLE PART DIMENSIONAL ANALYSIS.

Child parts are stamped sole panels which are received from supplier. Panel level dimensional inspection will helps to identify assembly level impact which may lead to panel twist when locating the panels one another in fixture. After spot welding process part cannot be corrected to its original position. Since 
Locating devices on an appropriate location is part of dimensional and fixture integrity outcomes. Body sides outer panel, tail lamp part and lower pillar are rear end assembly sole panels.

\section{1.a. Body sides outer stamping panel}

Body sides stamping panel flange length is too short compared to CAD value shown in Fig 3, which has been measured for continuous 3 bodies since to fix the root cause as stamped panel batch production. It has been observed in batch to batch samples tells that die repetitiveness. Iterative Die correction done to increase flange length as per CAD value so that panel pulling will not happen while welding so that flushness at paint band area can be achieved..
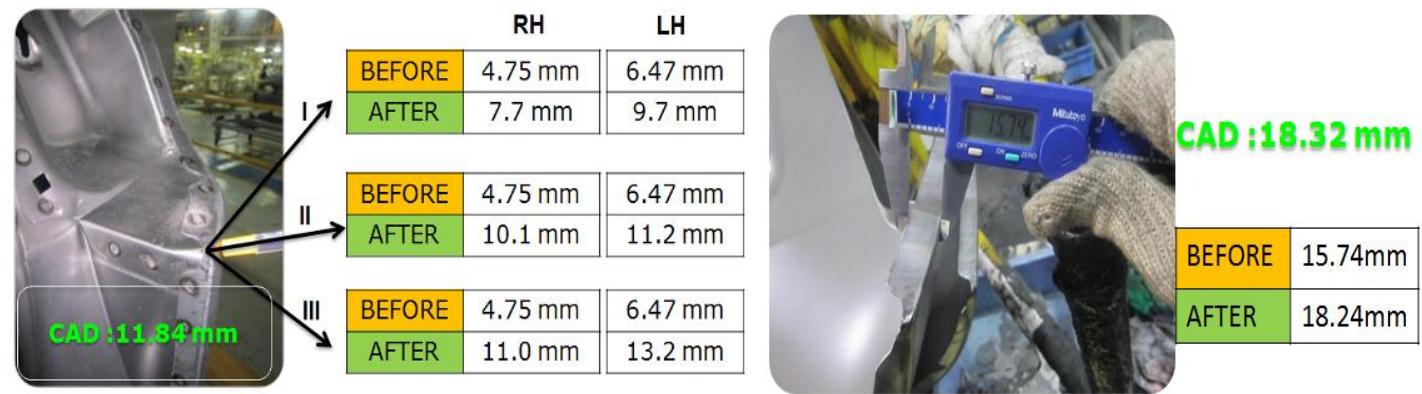

Figure 3 - Body Sides Measurement Data

\section{1.b. Tail lamp part and lower pillar}
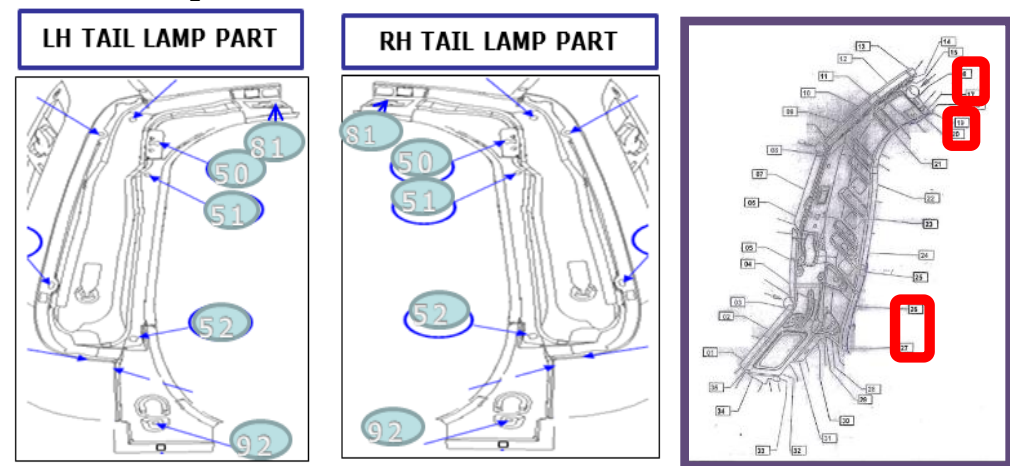

Figure 4 - Tail lamp part and Lower pillar

\begin{tabular}{|c|c|c|c|c|}
\hline $\begin{array}{l}\text { POIN } \\
\text { TS NO }\end{array}$ & LH & $\mathbf{x}$ & $\mathbf{Y}$ & z \\
\hline \multirow{3}{*}{50} & NOMINAL & 4457.8600 & -479.7400 & 1414.7100 \\
\hline & ACTUAL & 4457.7959 & -483.1155 & 1413.5036 \\
\hline & DEVIATION & -0.0641 & 3.3755 & -1.2064 \\
\hline \multirow{3}{*}{51} & NOMINAL & 4485.0500 & -506.4600 & 1342.0000 \\
\hline & ACTUAL & 4486.1018 & -506.3471 & 1341.7866 \\
\hline & DEVIATION & 1.0518 & -0.1129 & -0.2134 \\
\hline \multirow{3}{*}{52} & NOMINAL & 4718.6100 & -575.1000 & 999.4100 \\
\hline & ACTUAL & 4719.9790 & -572.1295 & 999.8177 \\
\hline & DEVIATION & 1.3690 & -2.9705 & 0.4077 \\
\hline \multirow{3}{*}{81} & NOMINAL & 4400.8200 & -306.3100 & 1491.3200 \\
\hline & ACTUAL & 4401.2883 & -306.6222 & 1491.9532 \\
\hline & DEVIATION & 0.4683 & 0.3122 & 0.6332 \\
\hline \multirow{3}{*}{92} & NOMINAL & 4786.1100 & -555.0000 & 798.0000 \\
\hline & ACTUAL & 4788.2526 & -553.7723 & 797.7535 \\
\hline & DEVIATION & 2.1426 & -1.2277 & -0.2465 \\
\hline
\end{tabular}

\begin{tabular}{|c|c|c|c|c|}
\hline $\begin{array}{l}\text { POINTS } \\
\text { NO }\end{array}$ & RH & $\mathbf{x}$ & $\mathbf{Y}$ & z \\
\hline \multirow{3}{*}{50} & NOMINAL & 4457.8600 & 479.7400 & 1414.7100 \\
\hline & ACtuAl & 4456.2319 & 481.5361 & 1416.0356 \\
\hline & DEVIATION & -1.6281 & 1.7961 & 1.3256 \\
\hline \multirow{3}{*}{51} & NOMINAL & 4485.0500 & 506.4600 & 1342.0000 \\
\hline & ACtUAL & 4486.1593 & 506.7689 & 1342.2361 \\
\hline & DEVIATION & 1.1093 & 0.3089 & 0.2361 \\
\hline \multirow{3}{*}{52} & NOMINAL & 4718.6100 & 575.1000 & 999.4100 \\
\hline & ACtUAL & 4720.9695 & 573.4274 & 1000.6323 \\
\hline & DEVIATION & 2.3595 & -1.6726 & 1.2223 \\
\hline \multirow{3}{*}{81} & NOMINAL & 4400.8200 & 306.3100 & 1491.3200 \\
\hline & ACtuAl & 4401.1046 & 306.5607 & 1491.7462 \\
\hline & DEVIATION & 0.2846 & 0.2507 & 0.4262 \\
\hline \multirow{3}{*}{92} & NOMINAL & 4786.1100 & 555.0000 & 798.0000 \\
\hline & ACtUAL & 4787.9578 & 554.2515 & 800.0618 \\
\hline & DEVIATION & 1.8478 & -0.7485 & 2.0618 \\
\hline
\end{tabular}

Table 1 - Tail Lamp points

Tail Lamp part and lower panel as shown in Fig 4, is base panel to the tail lamp trim part which is being welded with body sides outer panel. Tail lamp mounting hole decides the tail lamp location in car so that system 
can ensure the tail lamp rubbing with tailgate relation. Supplier end Tail lamp part deviates at gas stamper mounting sphere as shown in Table 1, hence tail lamp mounting points and bump stopper position and lower pillar deviations are corrected at incoming fixtures.

\section{SUB ASSEMBLY DIMENSIONAL ANALYSIS}

Sub-assemblies are denoted that 2 or 3 sole panels spot welded together by locating on assembly fixtures. To validate child part level improvement and actual condition of sub assembly level parts, it is important to study on sub assembly deviation. This will helps to know part level variation or process deviations.

\section{2.a. Body Sides Assembly}

Body sides assembly tail lamp mounting surface is checked with PCF and shows RH roof header point deviated in $-2 \mathrm{~mm}$ in $\mathrm{Y}$ direction and $\mathrm{LH}$ roof header point deviated in $+3 \mathrm{~mm}$ in $\mathrm{Y}$ direction which indicates root cause of assembly level deviation. To identify the actual deviation, the same two bodies are measured in CMM.

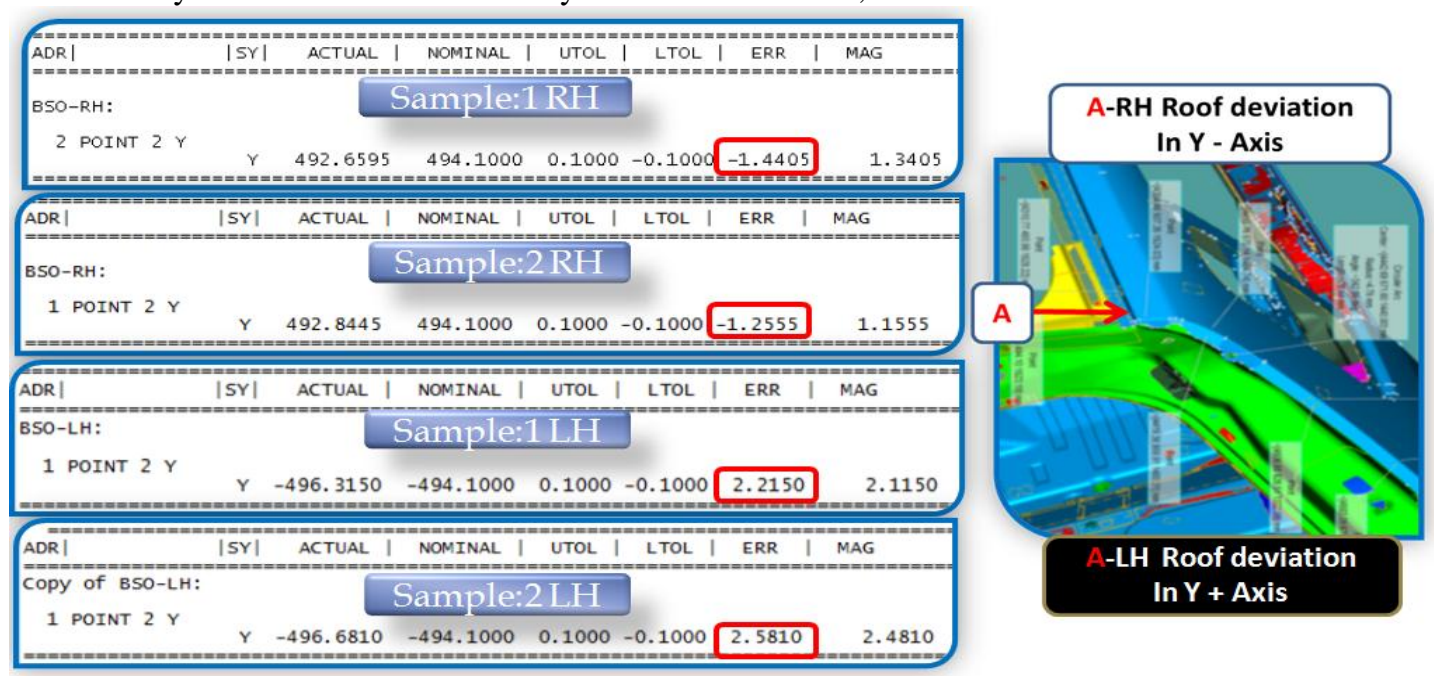

Figure 5 - Body Sides CMM Measurement

Based on CMM report shown in Fig 5, Shim correction is done to bring the roof header points towards nominal.

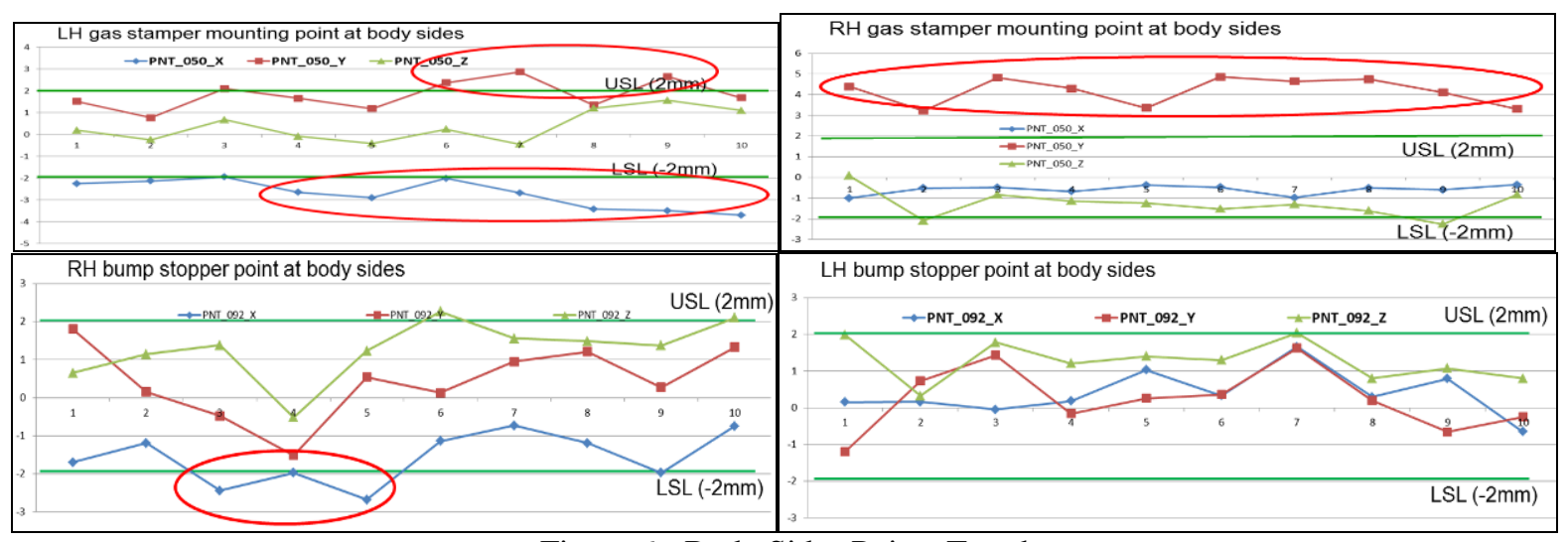

Figure 6 - Body Sides Points Trend

Above dimensional deviation in gas stamper sphere and bump stopper points is because of incoming level child part deviation which has been corrected at supplier end parts fixtures results shared in Fig 7. Gas stamper mounting deviation restricts easy piston movement results hard to close tailgate. 


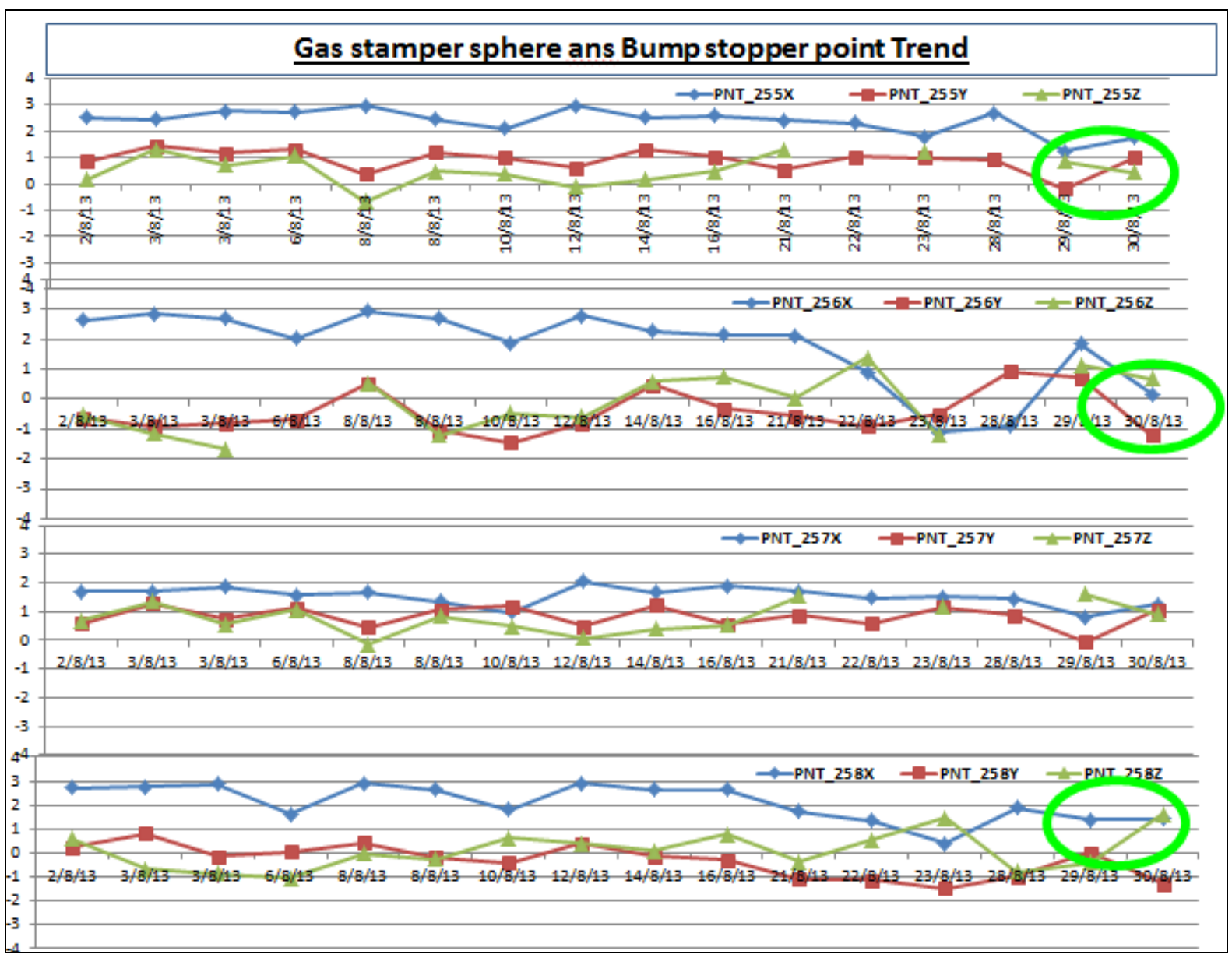

Figure 7 - Body Sides Points trend - After correction

\section{2.b. Underbody Asssembly}

Underbody back panel striker mounting hole position and back panel flange place an important role for seal gap. PCF scrubbing shows that back panel striker mounting hole have deviation at $\mathrm{X}+$ direction as shown in Fig 8. which is corrected at Rear Floor panel. $\mathrm{X}+$ deviation results long travel of tailgate and improper latching.
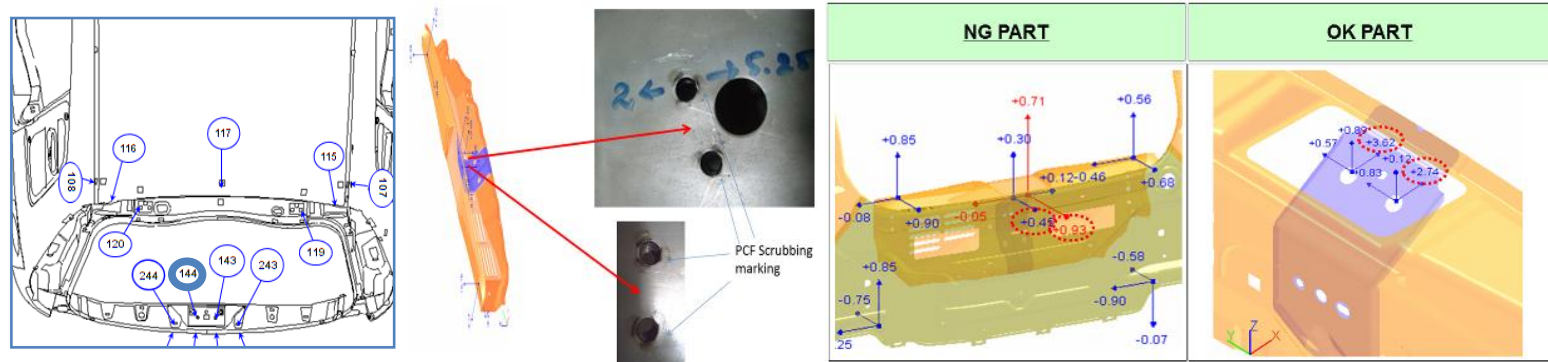

\section{2.c. Tailgate}

Figure 8 - Back Panel PCF Scrubbing and Scan Report

Tailgate Latch mounting point is important parameter in Tailgate and those points are well within specification as shown in Fig 9. Latch is the Plastic member and the fulcrum in Latch will hit against the striker so that locking will happen. Uneven latching results improper closing and rattle noise. 


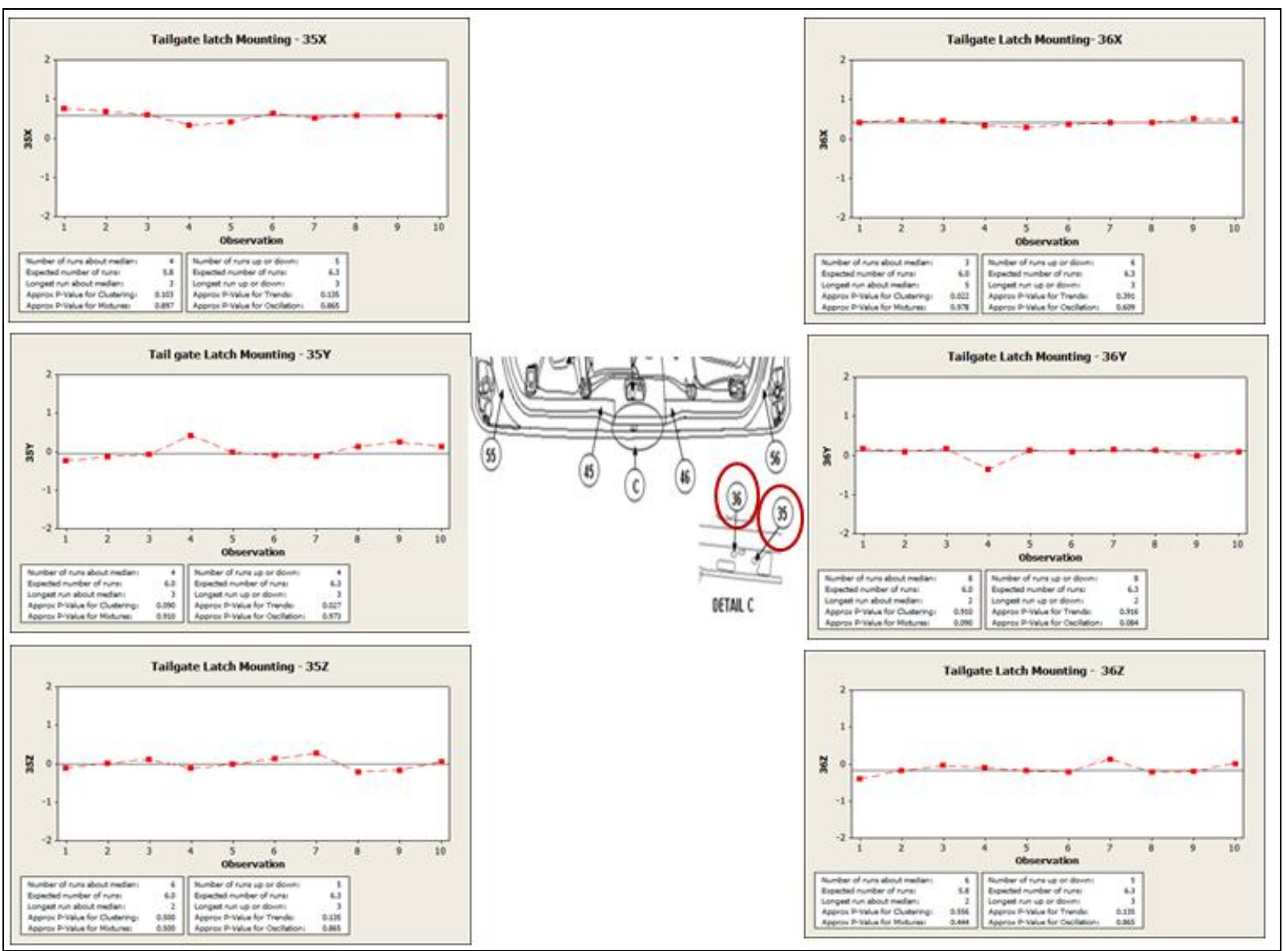

Figure 9 - Tailgate points Trend Chart

\section{2.d. Roof Assembly}

Roof is flimsy panel reinforce with thicker panel is called Roof bow. Roof bow is having tail gate hinge mounting Master control Hole. Tailgate hinge mounting point at Roof bow dimensional capability $\mathrm{Cp}$, Cpk>1.33 as shown in Fig 10 describes process is more stable and capable.
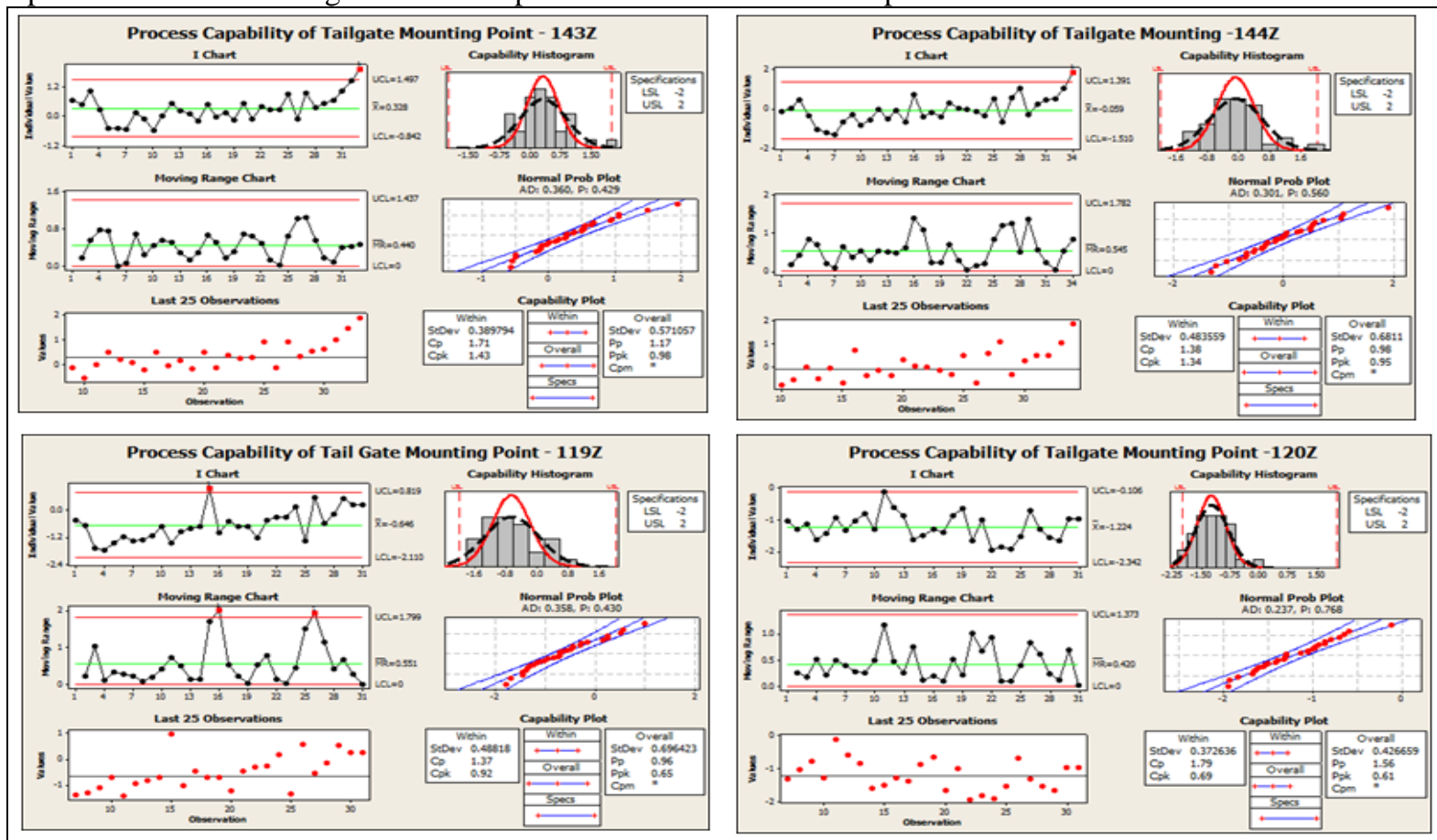

Figure 10 - Roof Points Six Pack Chart 


\section{FRAMED BODY DIMENSIONAL ANALYSIS}

Framed body is final body shell where sub-assemblies like body sides LH, body sides RH, Underbody and roof, are welded together, when it located in framing gripper. As a framed body level Tailgate hinge mounting, sticker mounting, bump stopper resting surface, Back panel flange trend will play the important role for seal gap. Back panel flange is having higher deviation and others are within specification indicated in Fig 11.

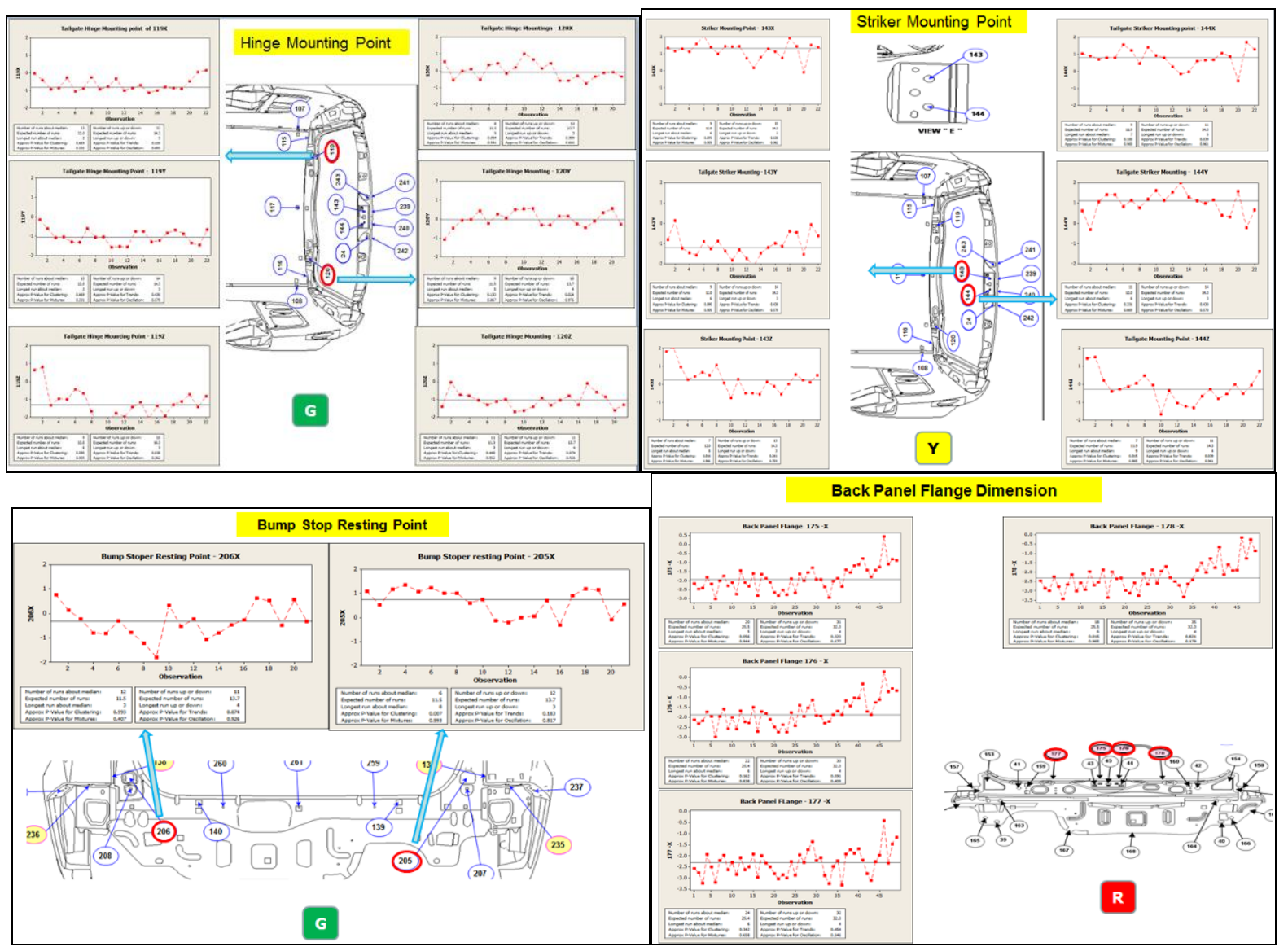

Figure 11 - Framed body Points Trend Chart

To bring the Back panel deviated points, shim correction done at rear floor fixture RF40 in $1.5 \mathrm{~mm}$ in $\mathrm{Z}$ direction since there is a panel gap between mylor to panel shown in Fig 12, which caused improper resting of panel on locating fixture.
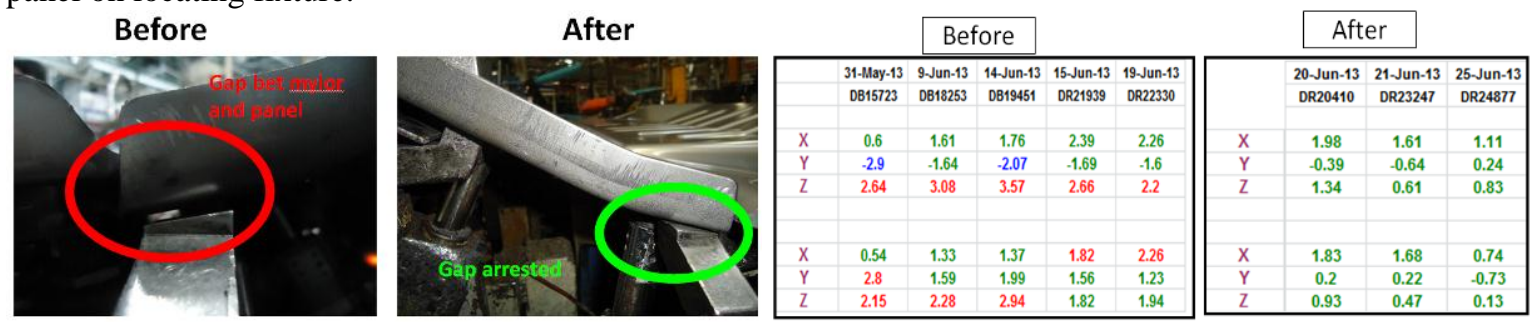

Figure 12 - Back Panel Fixture and correction results

\section{SEAL GAP AND MARGIN \& FLUSHNESS ANALYSIS}

Seal gap is the gap between flanges to tailgate resting surface. As per control plan seal gap should meet $C p>1.33$ and $C p k>1.33$. Seal gap will be measured by LMI gauge. Seal gap inversely proportional to closing effort which means high seal gap gives low effort whereas less seal gap gives more effort to close and open the tailgate. Seal gap has the design limitations. To reduce the closing effort, increasing the seal gap leads to water leak and air leak issue.

Gap and flushness is the outer appearance and wind noise parameters. These will contribute to seal gap tendency also. Tail gate to paint band area, tail gate more under flush leads to less seal gap. As shown in Fig 13 , rear end seal gap points meeting the capability with above action. 


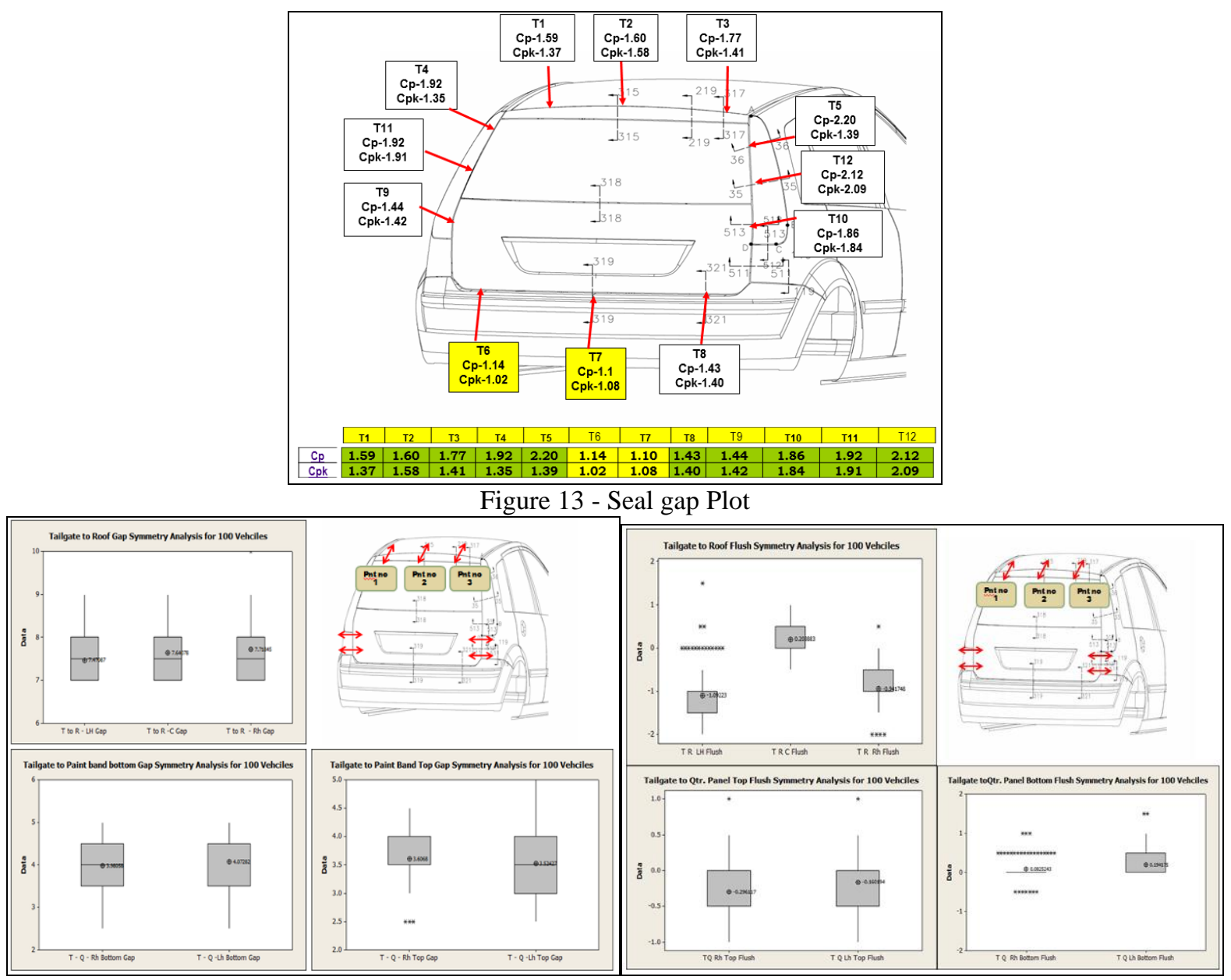

Figure 14 - Margin and Flushness Box Plot

Gap and flushness data is within a specification shown in Fig 14 and it is purely related to door setting skills.

\section{WEATHER STRIP ANALYSIS}

Weather strip is fitted in vehicle for multiple reasons which are air leak, water leak, wind noise, road noise, closing effort. Graph shown in Fig 15 is Performance curve of weather strip which is fitted in tailgate and framed body flange area as against Seal gap. Desired state of this cure should be flat in Y value at a given seal gap means irrespective of seal gap weather strip CLD should not change.

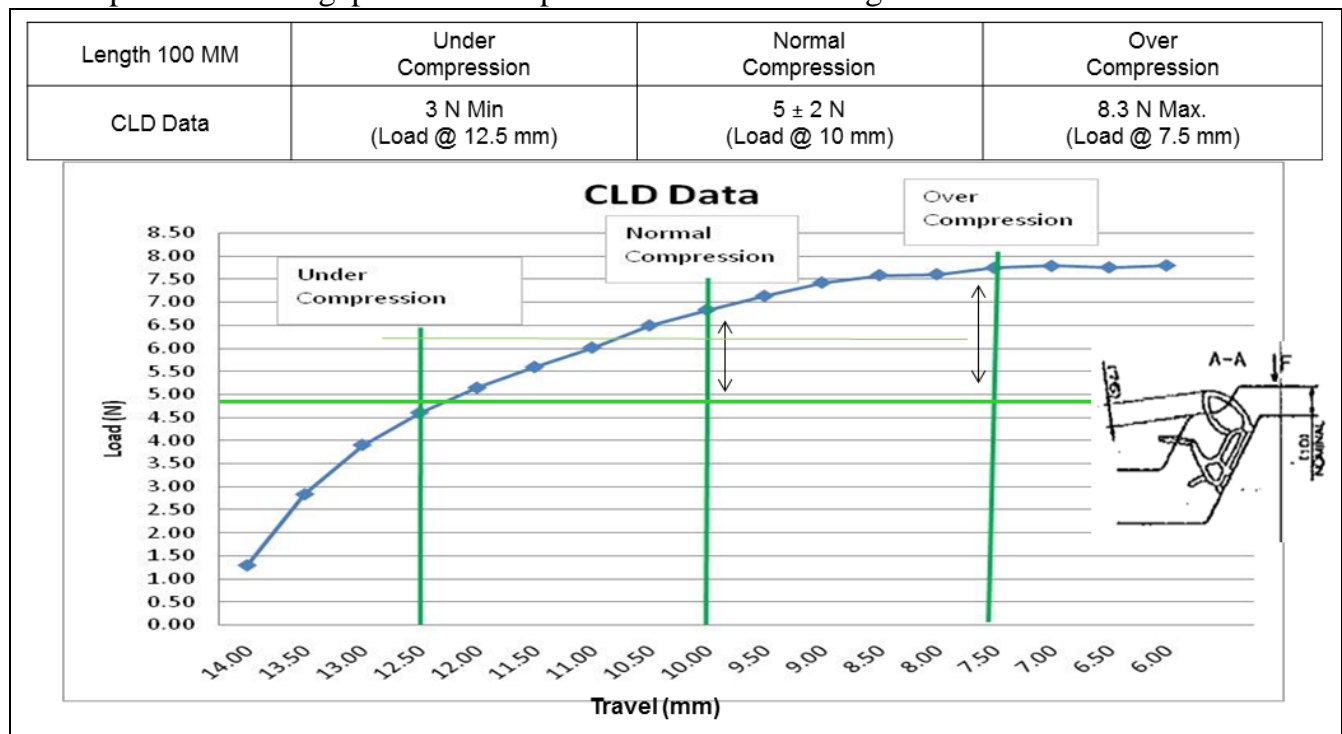

Figure 15 - Weather strip CLD Performance 


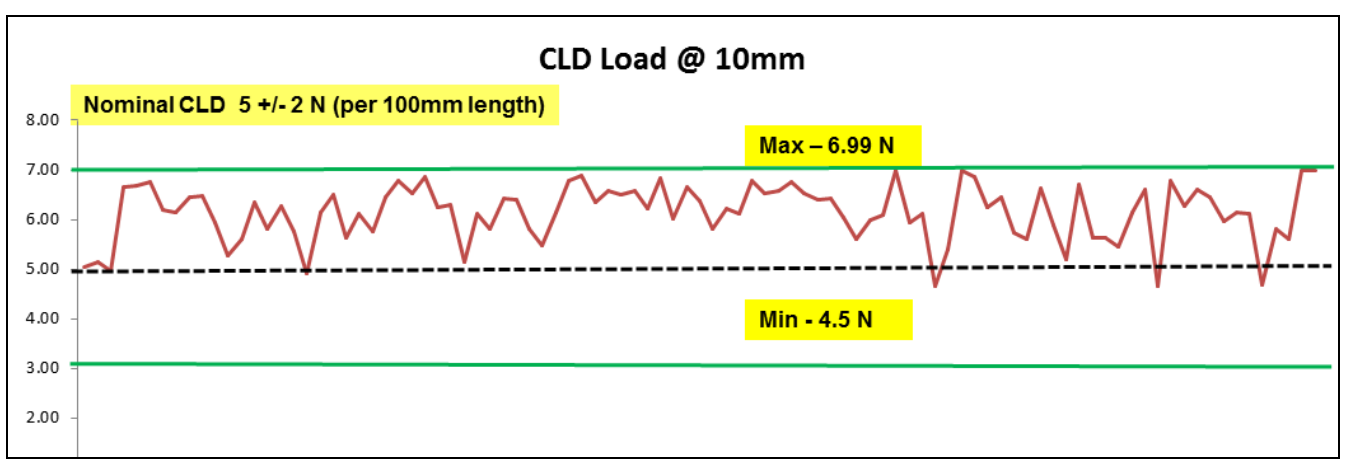

Figure 16 - CLD trend for 100 samples

CLD data shown in Fig 16 describes 100 samples giving very good repatability but upper band of CLD range. Refer Fig 17. It can be brought to nominal by increasing number of gas out holes in weather strip pulb.

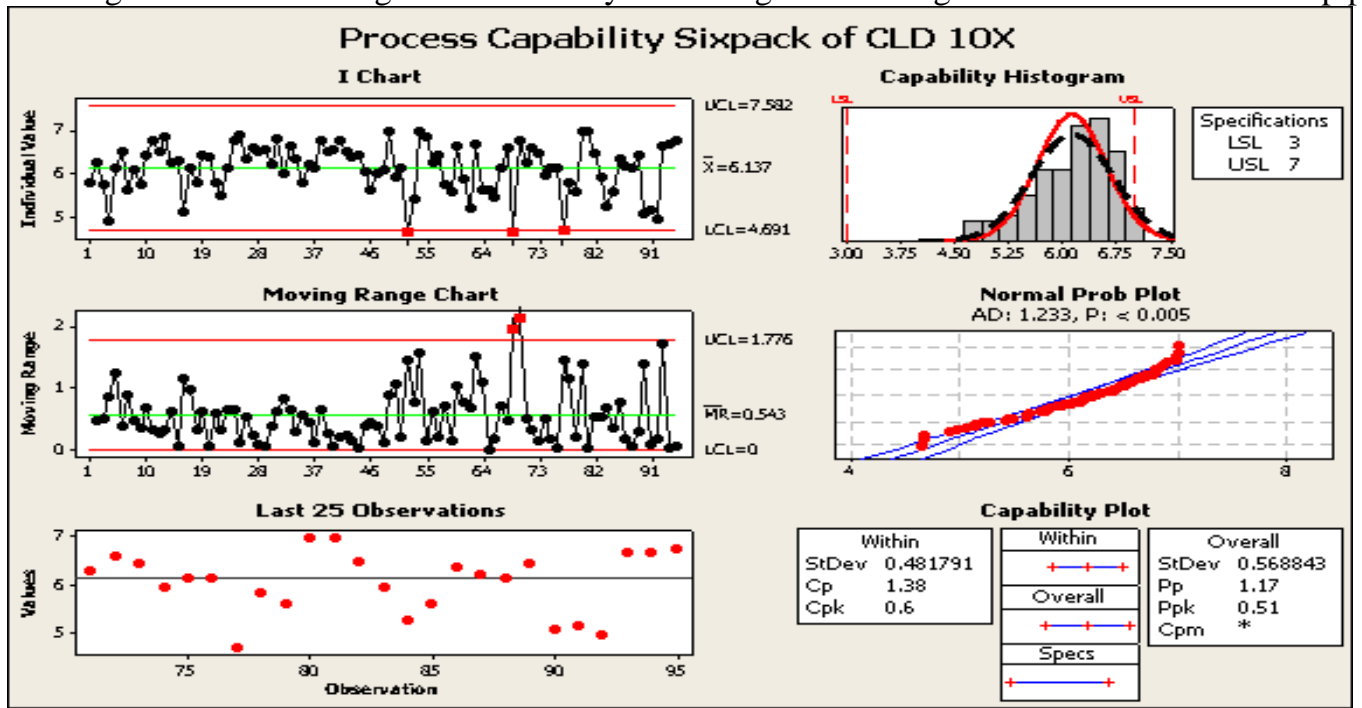

Figure 17 - CLD Capability chart

\section{CONCLUSION}

To reduce Tailgate closing effort, dimensional analysis in BIW level starts with child parts, sub assembly level and framed body is done.

Incoming level Sole part Body sides outer panel flange deviations corrected to bring towards CAD nominal in Paint band area. Tail Lamp part gas stamper mounting sphere deviations are corrected in incoming level.

Body sides roof header point corrections are done to take Y inboard and out board. Gas stamper sphere, bump stopper position are brought to specification. Underbody back panel position and striker mounting positions are corrected.

Framed body level back panel flange is corrected by arresting gap between mylor and panel. Back panel Seal gap brought to nominal by providing special type of tool to straighten the flanges. Molding.

Weather strip CLD (Compression Load Deflection) reduced to nominal by adding extra gas out holes in

With the above actions, BIW dimensional brought to specification at rear end and Weather strip CLD towards nominal correction done and tailgate closing effort is measured for running model. Project outcome helps to bring tailgate closing effort towards desired state as shown in Fig 11. 


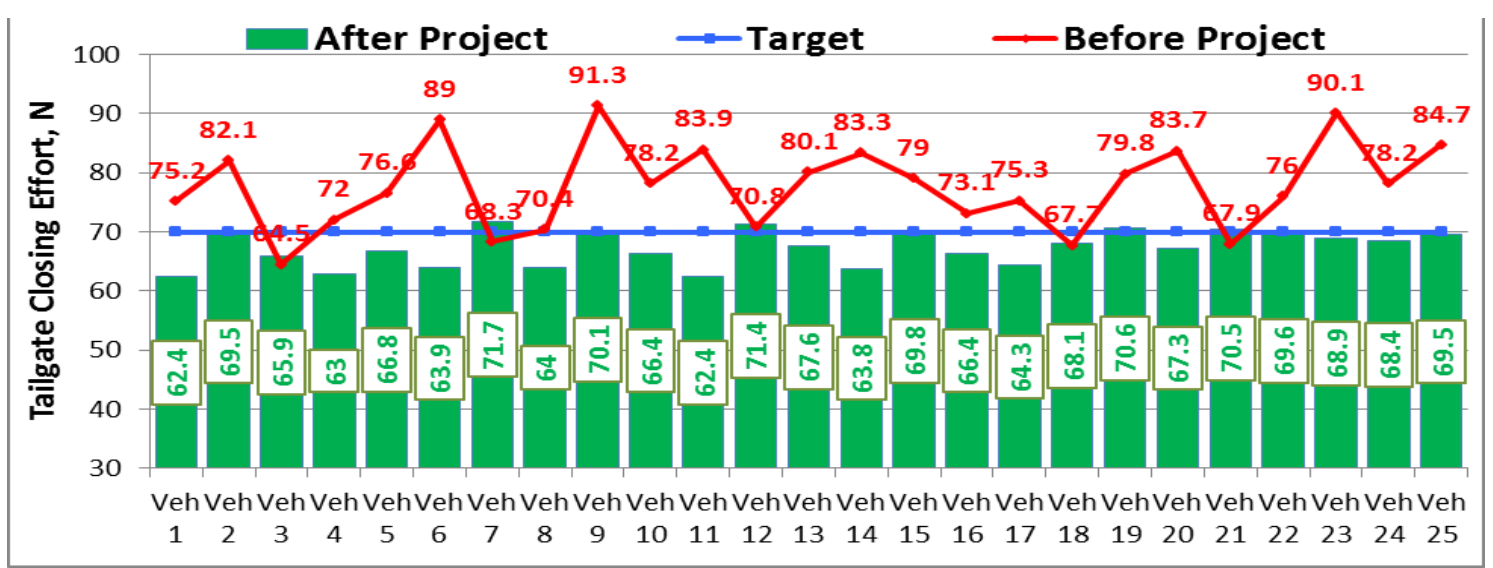

Figure 11 - Tailgate Closing Effort Result

\section{ACKNOWLEDGEMENTS}

I express my deep sense of gratitude and thanks to my guide Dr. G.Devaradjane, Professor and Head, Department of Automobile engineering, Madras Institute of Technology, Anna University, Chennai for allowing me to do project and continuous encouragement for doing this project. I also wish to express my deep sense of gratitude to Mr. K Yogesh Kumar, Team Manager, Body Construction, Ford India Pvt Limited, Chennai, for giving me an opportunity to do this project in the industry quality environment.

\section{REFERENCES}

[1] "National Car Test(NCT) Manual 2012 for Passenger Vehicle".

[2] Markus Kevis, (2004), "Door closing and Opening efforts and energies" CAE Value AB paper

[3] Dariusz Ceglareknd and Jiangun Shi (1995), "Dimensional Variation reduction for Automotive Body Assembly". Case study, S.M.Wu Manufacturing Research centre, University of Mechigan.

[4] L.M.Sanches Jr, M.S.Filho, and G.F.Batalha (2008), "Automotive body-in-white dimensional stability through pre control application in the sub assembly process", Journal of Achievements in Materials and Manufacturing Engineering (AMME). Vol 31, Issue2.

[5] F.Keith, G.Crisp and J.Aube, (1999), “Automotive Body Measurement System Capability” Publications of Auto Steel Partnership Members.

[6] T.T.Allan, R.W.Ritchardson, D.P.Tagleabue and G.P.Maul (2002), "Statistical Process Design for Robotic GMA welding of Sheet metal". Welding Journal by American Welding Society and Welding Research Council.

[7] Daniel E. Whitney, (2008), "Design and Manufacturing of Car Doors: Report on visits made to US, European and Japanese car manufacturer". MMRC Discussion Paper 202, University of Tokyo.

[8] A. Stenti, D.M.Moens and W.Densmet, (2004), "Dynamic modeling of car door weather seals: A first outline". Journal of K.U.Leuven, Department of Mechanical Engineering, division PMA.

[9] Joseph Thomas, (2001), "Mechanical properties and durability of natural rubber compounds and composites" Doctor of Philosophy in Material Science, Blackburg, Virginia.

[10] Jere Anderson, Eric P. Jurdain, (2005), "TPV Sponge materials and foaming systems for dynamic automotive weather seals". Journal by Extrusion Technical Director, Trexel. 